\section{Love or money?}

SIR - If I were an executive of a pharmaceutical company, I would do what is now happening almost monthly. Instead of increasing research in my own company, I would buy into a research outfit with its own source of funds. One problem is that, in the United States, as I am sure also in the United Kingdom, such research is supported by public funds.

Sandoz, for example, for an input of $\$ 300$ million to Scripps Research Institute (see Nature 362, 400; 1993) is not only buying into $\$ 1.3$ billion of National Institutes of Health funding during the lifetime of the Sandoz grant, but it is also buying into the millions of dollars that has gone into Scripps in previous years, which has undoubtedly formed the basis of present research at Scripps.

In other words, research is being bought up rather cheaply. In the example cited, Sandoz has in effect placed a lien on research at Scripps, preventing the results of that research from being presented to the open market. Scripps benefits, Sandoz will probably benefit, but the taxpayers will suffer.

What is to be done? One possibility is to insist, through regulation, that any company which has bought, even indirectly, into publicly sponsored research should recompense the public sponsor for research that has been the basis of any particular findings and that has led to a commercial product. Another possibility is to have those companies invest directly in the public sponsor. Think how many additional grants would accrue. Finally, the public sponsor should insist that once a private corporation has funded a researcher, no further grants should be made to that individual; a system of support that mixes profit and not-for-profit funds cannot be ethically maintained.

What we are witnessing, in the setting up of corporations by scientists, is the increasing privatization, for personal profit, of science as a public cooperative enterprise. What has become of the love of science, of research, of simple satisfaction with a job well done?

\section{Phillp Slekevit}

Rockfeller University,

1230 York Avenue,

New York, New York 10021-6399, USA

\section{Mammoth task}

SIR - It is altogether appropriate that the recent discovery of remains of dwarf mammoths on Wrangel Island off the northern coast of Siberia (Nature $\mathbf{3 6 2}$, $337-340 ; 1993$ ) should be announced in the year of the 250th anniversary of Thomas Jefferson's birth. In fact the paper came to my attention on 13 April, Thomas Jefferson's birthday.

Jefferson was much interested in mammoths ${ }^{1}$. He had mammoth bones in his collection at Monticello. In his advice to Andrew Michaud, the French botanistadventurer whom he had recruited for an abortive exploration of the American Northwest (of that day, 1793, not the "Northwest" of Lewis and Clark, more than ten years later), Jefferson wrote: "Under the head of Animal history, that of the Mammoth is particularly recommended to your enquiries"

Jefferson has long been derided by formal biologists for what they interpret as a naively romantic projection of palaeontology. His reputation as a naturalist is somewhat redeemed by the discovery of mammoth remains barely 4,000 years old, well within the period of written history (no writing or human remains on Wrangel lsland, however).

Jefferson also long took issue ${ }^{3}$ with Georges-Louis Buffon, the French botanist, for his thesis that species deteriorated as one moved west. Buffon said that mammals (including human beings) native to the Western Hemisphere were smaller than those from the Eastern Hemisphere and less amenable to the effects of civilization. Jefferson spent several years obtaining a skeleton and a hide of a North American moose to send to Buffon ${ }^{4}$. Although these specimens did reach Paris, Buffon, who was terminally ill, probably never saw them ${ }^{5}$. Jefferson would feel redeemed further that the Old World mammoths are small. We have big ones here.

\section{John M. Kissane}

Department of Pathology,

Washington University School of Medicine, Campus Box 8118 ,

South Euclid Avenue,

St Louis, Missouri 63110-1093, USA

1. Jefferson T. Notes on the State of Virginia. (ed. Peden, W. 43-47, 53-57 (Norton, New York, 1954).

2. Jefferson, T. to Mr. Andrew Michaud, 30 April 1793 in Thomas Jefferson and the Stony Mountains (ed. Jackson, D.) $71-77$ (Univers

Chinard, G. Eighteenth Century Theories on America as a Muman Habitat 27-57.

Muman Habitat $27-57$.
Boyd, J. P. (ed.) The Papers of Thomas Jefferson Vol. 9 , 160: Vol. 11, 68, 320 (Princeton University Press 1950-)

5. Lacepede to T.J. in Letters of the Lewis and Clark Expedition with related Documents, 1783 -1854 (ed. Jackson, D.) 2nd edn, 46-48 (University of Illinois Press. Urbana).

\section{Physics of life}

Sir - John Maddox (Nature 363, 13; 1993) has demonstrated what can only be regarded as an extreme form of reductionism. Here, even restrained, he chastises molecular biology for a preoccupation with "enumeration" and "competitiveness", the former serving to keep molecular biology, as we are led to infer, failed of its true potential as a science. (The latter complaint is a red herring, as anyone who has ever read anything about the Super- conducting Super Collider or similar projects will know.) If only molecular biologists were more rigorous - indeed, as Maddox clarifies, more like "physical chemists" - then their craft might prove invaluable as a means to "understanding" what's really going on in nature. But, I wish to interject, what is it that Maddox thinks is really going on?

Suppose we ask for the most complete explanation of any particular event, what would count as such? Maddox would surely admit that for hundreds of years there were many scientists who assumed that no complete explanation of physical events could be given without the invocation of divine power. Descartes, for example, crafted a dualism for the sake of giving what he thought was a complete explanation of the mind and the body. Even today, issues in the philosophy of mind and psychology turn on the question of the level of ontology of explanations: surely neurophysiological explanations of our wants and desires will some day be possible, but that does not mean that intentional explanations (for example, 'he took a drink because he wanted water') are any less complete and genuine as lower level physical explanations.

What we need to focus on in any level of explanation is the nearness to lawfulness that is achieved: counterfactual supporting generalizations in any of the special sciences should probably be considered laws (ceteris paribus, though they be). Hence, table-thumping reductionism, as Maddox gives, serves no purpose, instead it merely demonstrates an ignorance of the many levels of scientific inquiry - the different laws and ontology - that are possible. Now, are all of these levels to be explained by physics alone? I think not, though this is not a retreat to a pernicious dualism. Instead, it is to emphasize the rather hefty price one must pay for reductionism.

Poor Descartes, he is in such bad favour these days, what with all the scientific progress around. But is it really sensible to pull back all the way to the other side, to go physicalist come what may? Hardly. Molecular mechanisms across many species are indeed interesting, but surely one of the most intriguing things is to look at this the other way round: how could the same molecular mechanisms subvene for different species? I submit that the microlevel sciences (physics for example) could never answer such a question, as it occupies a place outside that domain. But then so do many other intriguing questions, like many that molecular biologists ask.

Come on, Mr Maddox, let's all pull together.

\section{Douglas Braaten}

Department of Biological Sciences, Columbia University,

New York, New York 10027, USA 